\title{
Social work in the Pacific: The humble and unrefined views of a non-social worker
}

Steven Ratuva, University of Canterbury, New Zealand

\begin{abstract}
I once worked in a university where sociology and social work were part of the same department, which I headed. I observed how social work, more than most "disciplines," was readily responsive, quickly adaptive and empowering with the potential to be readapted and aligned to suit different socio-cultural contexts. From the vantage point of a non-social worker, this makes it resilient and relevant in a fast-changing world where conflict, wealth accumulation and the creation of expanding subaltern classes take place simultaneously. As peripheral "participants" in the process of corporate, technological and cultural globalisation, Pacific Island countries (PICs), often see themselves increasingly subaltern in the global economic and political power game as manifested in increasing poverty, social dislocation, debt, crime and other social problems.

A growing capacity for responsiveness, adaptation and empowerment requires a critical approach to understanding the complexities of social dynamics and impact on human wellbeing. Social work crosses the arbitrary boundaries between sociology, anthropology, psychology, development studies, conflict/peace studies, education and health and this trans-disciplinary approach makes it well positioned to address issues such as inequality, poverty, alienation and marginalisation which are common amongst subaltern groups, including those in the Pacific (Sherif \& Sherif, 2017). Social work also has the potential to bridge the gap between theory and practice in what Marxian scholars refer to as "praxis" (Freenberg, 2014). Its strength is also in keeping human wellbeing as the central focus in its analysis.
\end{abstract}

KEYWORDS: social work; interdisciplinary; Pacific; empowerment; wellbeing; community

\section{Pacific praxis: The context}

Although I am not a trained social worker, my interdisciplinary background in sociology (my primary "discipline"), politics, anthropology, development studies, peace-conflict studies, history and economics, has provided me with an appreciation of how social work, with its transdisciplinary potential, can be reengineered to meaningfully engage with Pacific communities in the islands. Pacific Island societies, although geographically small, are highly complex with strong interconnections between social, economic, cultural and political institutions, norms and values. They have been framed as "syncretic" societies (Ratuva, 2005) because of the complex processes of interactions occurring between the global and local systems and narratives. Rather than forming a "hybrid" system, as Clements, Boege, Brown, Foley, and Nolan (2007) argue, these interactions are manifested in complex configurations which involve the simultaneous existence of contradictions, resistance, accommodation, acceptance, integration and synthesis. For instance,
AOTEAROA NEW ZEALAND SOCIAL WORK 30(4), 5-8.

CORRESPONDENCE TO: Steven Ratuva steven.ratuva@ canterbury.ac.nz 
while there is some resistance against capitalist profit motives by those engaged in communal subsistence production, there is also accommodation of the idea of being rich. Capitalism and subsistence production are not always in opposition; there are also moments of accommodation and synthesis where people choose aspects of both in order to survive. This syncretic relationship pervades other aspects of Pacific Island life including communal and individual rights, Christianity and traditional cosmology, liberal democracy and indigenous governance, for example.

These complex, syncretic interactions can be potent driving forces for social transformation as well as sources of stress. As people move in large numbers to urban centres to escape a demanding village life to seek new opportunities, they are further burdened by lack of opportunities, unemployment and low income - these contribute to poverty, crime and other social problems. In the urban centres, variants of village social life are replicated through communal and kinship networking and, while this might work as a social safety net to facilitate resources distribution, it can also be a burden as people are expected to meet traditional obligations using meagre resources. The church also contributes to this stress through imposition of tithes and other religious obligations which further add to families' financial hardships.

In the main Pacific urban centres, squatter or informal settlements continue to grow unabated and a number of nuclear families might live under a single roof (Gero, Kohlitz, \& Willetts, 2017). This overcrowding leads to health issues, problems of social morality and an inability for children to study and excel in education. Health problems are exacerbated by a lack of money to buy nutritious food and thus people resort to eating cheap, high-carb, high-fat and highsugar food.

Family break-up is common and, in some Pacific countries, children are looked after by relatives - in some cases, children are taken into foster care homes. Family instability directly affects young people who sometimes end up committing crime. The culture of warrior masculinity in many Pacific communities, together with social stress and other socio-economic challenges, contribute further to family violence. Masculinity is reinforced through sports like rugby, church doctrines of male superiority, a patriarchal western education system, male-dominated power politics and cultural traditions which accord women inferior positions in the social hierarchy.

These issues are often concealed and distorted by a romantic notion of "paradise," propagated by tourist narratives as part of the process of neoliberal commodification of indigenous cultural imageries. The church's narrative on predestination and divine will, which preaches suffering on earth as pre-requisite for eternal salvation, has tended to legitimise inequality and poverty as natural. Often social workers, aid donors, governments and others dealing with these issues look at only the social manifestations of the problems without considering the ideological systems which help sustain and legitimise them. To address these issues effectively, social work in the Pacific needs to be framed and designed in a way that takes into consideration the syncretic interplay between the different factors and how they shape the conditions for nurturing poverty, social dislocation and marginalisation.

These problems are quite visible and are inescapable. But they should not be used to denigrate local communities but, rather, they should be used to create windows of opportunities to identify forms of cultural capital which can be used to empower and build up resilience. Pacific communities have, over the ages, developed mechanisms for survival and adaptation and the challenge is how to incorporate these into social work approaches. Social work in the Pacific needs to adopt a social protection stance in responding to these critical issues. Rather than just responding to the symptoms 
and visible manifestations of the problems, it must aim at understanding and seeking solutions to the root causes.

\section{A sociologist's advice for social workers}

When C. Wright Mills (2000) coined the now overused but perpetually relevant notion of "sociological imagination," he was wary of the mainstream disciplinary trend of myopic intellectualism and moral selfrighteousness, which were enshrined at the sacred altar of academia. He saw the need to map out the world in terms of trans-national, trans-personality, trans-issue and transeverything connections, where the public and the private, history and the future and the "me" and the "them" are linked in a web of transformational synergies and connections. Social work must be inspired by the virtues of sociological imagination. This means being aware of the shifting social environment which shapes social issues and responding to these in new, innovative and creative ways. The rise in counter-hegemonic movements such as the reclaim the city movement, the me too movement, Bernie Sanders' youth revolution and groundswell of anti-Trumpism around the world are taking place in parallel to the growth in right-wing and racist politics. Social work, like any other discipline, needs to be cognisant of these developments and make an ideological and political stand. It must transcend its own boundaries, extend its sociological imagination far and wide and respond to emerging threats while embracing new hopes and opportunities in creative and innovative ways.

Often, when social work is institutionalised (especially by the state and service providers), it can become mundane, routine and leveraged for bureaucratic policy. This is what happens in many, if not all, the PICs. For instance, the social work unit at the University of the South Pacific which has been part of the sociology department for many years, has always been closely aligned to the regional government welfare departments to provide training for their welfare officers. While this is fine in relation to providing direct service to the public, the external control of university courses to suit a narrow external interest has potential to undermine creative, empowering and innovative initiatives which are transformative, as opposed to those which reinforce existing policies and associated political agendas.

Another challenge is how to make social work culturally relevant in the Pacific, especially when it is conventionally associated with urban issues such as unemployment, crime, poverty and other urban-based problems. In a region where most people still live in rural and semi-subsistence conditions and where culture still revolves around kinship and communal support systems, the image and role of social work need changes. For a start, the term "social work" itself needs contextual reconfiguration into something like "community engagement" to ensure that it "fits" into the local communal milieu and cultural narrative. "Social workers" can continue to work in more urbanised situations while "community engagement officers" can work in more rural settings. Terminologies have the potential to frame people's sense of reality and can also impact on behaviour and outcomes.

The work of the community engagement officers must reflect the syncretic changes taking place in rural areas and how best they can facilitate the transition and respond to emerging social problems in an empowering way. They need to deal with issues such as gender inequality and patriarchal hegemony which have been erroneously framed and justified as "cultural" in ways which are socially acceptable and transformative. Disputes over titles and land rights have caused communal instability in many villages in the Pacific and so the community engagement officers must be equipped with conflict resolution and peace-building skills.

In an age of globalisation where even the most remote Pacific villages are 
connected by mobile phone, it is prudent to use both new and traditional modes of communication and engagement to maximise convenience and results. While modernity and its influences are imperative, how we deal with these to serve our purposes must be approached critically and strategically. Social work must provide the skills for empowering adaptation rather than facilitate passive domestication and subservience to globalization forces.

There was a time when anthropologists descended on the Pacific and used it as a laboratory for studying both "noble" and "ignoble" "savages" and the impact of their narratives remain embedded in contemporary subconscious prejudice and racial stereotypes of islanders. Historically, the narratives articulated by such as Bronislaw Malinowski, Raymond Firth and Marshall Sahlins about Pacific tribal societies with unsophisticated and backward social systems have become the basis for constructing contemporary racialised imageries associated with Pacific peoples (brawny with no brain, welfare leeches, violent, crime-prone and unhealthy). Social workers have a responsibility as agents of empowerment and transformation to transform and de-mythologize such perceptions, deconstruct negativities and create positive conditions for an energised diverse world.

Today, a substantial number of Pacific peoples make up the diaspora community and in their new cultural habitats, they have established social networks, support systems and cultural norms which reflect both their historical Pacific heritage and new social environment. As in Aotearoa New Zealand, this new diaspora has a new set of needs and expectations which must be understood and responded to. Social workers must have the critical intellectual narratives and relevant methodological tools to address these new challenges. It is their disciplinary calling. It is their moral responsibility. It is an opportunity to showcase who they are.

\section{References}

Clements, K., Boege, V., Brown, A., Foley, W., \& Nolan, A. (2007). State building reconsidered: The role of hybridity in the formation of political order. Political Science, 59(1), 45-56.

Freenberg, A. (2014). The philosophy of praxis: Marx, Lukacs and the Frankfurt school. London, UK: Verso.

Gero, A., Kohlitz, J., \& Willets, J. (2017). Informal settlements in the Pacific and links to sustainable development. Development Bulletin, 78, 91-96.

Mills, C. Wright. (2000). Sociological imagination. Oxford, UK: Oxford University Press.

Ratuva, S. (2004). Reconceptualizing contemporary Pacific islands states: Towards a syncretic approach. The New Pacific Review, 2(1), 246-262.

Sherif, M., \& Sherif, C. (Eds.). (2017). Interdisciplinary relationships in the social sciences. New York, NY: Routledge. 